\title{
Regional solar radiation is inversely correlated with incidence and severity of tuberculosis in Chile
}

\author{
M. E. BALCELLS ${ }^{1}$, J. CERDA ${ }^{2}$, S. CONCHA ${ }^{3}$, R. HOYOS-BACHILOGLU ${ }^{3}$, \\ C. A. CAMARGO JR. ${ }^{4}$, A. R. MARTINEAU ${ }^{5}$ AND A. BORZUTZKY $Y^{3,6 *}$ \\ ${ }^{1}$ Department of Infectious Diseases, School of Medicine, Pontificia Universidad Católica de Chile, Santiago, \\ Chile \\ ${ }^{2}$ Department of Public Health, School of Medicine, Pontificia Universidad Católica de Chile, Santiago, Chile \\ ${ }^{3}$ Department of Pediatric Infectious Diseases and Immunology, School of Medicine, Pontificia Universidad \\ Católica de Chile, Santiago, Chile \\ ${ }^{4}$ Department of Emergency Medicine and Division of Rheumatology, Allergy, and Immunology, Department of \\ Medicine, Harvard Medical School, Boston, USA \\ ${ }^{5}$ Barts and The London School of Medicine and Dentistry, Queen Mary University of London, London, UK \\ ${ }^{6}$ Millennium Institute on Immunology and Immunotherapy, School of Medicine, Pontificia Universidad Católica \\ de Chile, Santiago, Chile
}

Received 1 October 2016; Final revision 28 January 2017; Accepted 5 March 2017; first published online 3 April 2017

\section{SUMMARY}

Vitamin D (VD) deficiency has been linked to increased incidence and morbidity of tuberculosis (TB). Chile has large variations in solar radiation (SR; a proxy of VD status) and high prevalence of VD deficiency in its southernmost regions with low SR. We investigated the correlation between regional SR and rates of TB incidence, admissions and deaths in Chile by reviewing national records on prospectively collected mandatory disease notifications, admissions and mortality between 2001 and 2011. Over the study period, 26691 new TB notifications were registered. The TB incidence rate was $14 \cdot 77$ (95\% confidence intervals (CIs) 14.60-14.95), admission rate was 12.12 (95\% CI 11.96-12.28) and mortality rate was 1.61 (95\% CI $1.55-1 \cdot 67)$ per 100000 population per year. Multivariable linear regressions adjusting for significant demographic TB risk factors in Chile (regional prevalence of HIV infection, rates of migration from TB-endemic countries and rates of imprisonment) revealed an independent and highly statistically significant inverse association between SR and TB incidence rate $(\beta-1 \cdot 05,95 \% \mathrm{CI}$ -1.73 to $-0.36, P=0.007)$, admission rate $(\beta-1.58,95 \% \mathrm{CI}-2.23$ to $-0.93, P<0.001)$, and mortality rate $(\beta-0 \cdot 15,95 \% \mathrm{CI}-0 \cdot 23$ to $-0 \cdot 07, P=0 \cdot 002)$. These findings support a potential pathogenic role of VD deficiency in TB incidence and severity.

Key words: Epidemiology, sunlight, tuberculosis, vitamin D.

\footnotetext{
* Author for correspondence: A. Borzutzky, M.D., Department of Pediatric Infectious Diseases and Immunology, School of Medicine, Pontificia Universidad Católica de Chile, Diagonal Paraguay 362. Santiago, 8330074, Chile.

(Email: arturobor@med.puc.cl)
}

\section{INTRODUCTION}

Tuberculosis (TB) is a deadly infectious disease that continues to pose a major threat to global health. In 2014, an estimated $9 \cdot 6$ million people developed TB and 1.5 million died from the disease[1]. Several risk factors for TB development and mortality have been 
identified worldwide, most notably poverty and overcrowding, HIV infection, undernutrition, alcohol misuse, silicosis, diabetes, smoking, immunosuppressive therapy and end-stage renal disease[2]. However, these do not entirely explain variations in TB incidence reported in different countries and at different latitudes.

For more than a century, sun exposure has been identified as a possible protective factor for TB. Plenty of sun exposure and fish liver oil intake were considered important adjunct treatments of $\mathrm{TB}$ in the preantibiotic era. This protection has been attributed to vitamin $\mathrm{D}$ (VD) synthesis in human skin upon exposure to solar ultraviolet B (UVB) radiation and to the high VD content of fish liver oil, respectively. VD is a prepro-hormone whose active metabolite, 1,25-dihydroxy $\operatorname{VD}(1 \alpha, 25[\mathrm{OH}] 2 \mathrm{D})$ has multiple actions on the immune system and enhances immunity to mycobacteria, among other effects[3]. In most settings, the VD status of an individual is mostly determined by skin synthesis (i.e., sun exposure), with only a minor fraction acquired from dietary sources such as oily fish. Most experts agree that 25-hydroxyvitamin D (25OHD) $<50 \mathrm{nmol} / 1$ is an indication of VD deficiency, whereas 25OHD of $50-74 \mathrm{nmol} / 1$ indicates insufficiency and concentrations $\geqslant 75 \mathrm{nmol} / 1$ are considered to be sufficient[4].

In the last decade, several studies have shown that up to $30-50 \%$ of adults and children living in different geographical areas worldwide are at risk of VD deficiency, attributed to low UVB exposure and modern lifestyle[4]. Chile has a relatively unique geographical situation, being a long and slender country with large differences in latitude, from $17^{\circ} \mathrm{S}$ at the extreme north and $56^{\circ} \mathrm{S}$ at the extreme south (Fig. 1). Latitude has a high correlation with solar radiation (SR) in Chile $(r=-0 \cdot 96)$, with SR being high in the northern regions and reaching a minimum in the extreme southern regions[5]. In the city of Arica (extreme north, latitude $17 \cdot 5^{\circ} \mathrm{S}$ ) postmenopausal women were uncommonly found to have VD deficiency, with a median plasma $25 \mathrm{OHD}$ level of $64 \mathrm{nmol} / 1$, whereas in Santiago (central Chile, latitude $33^{\circ} \mathrm{S}$ ) studies have shown that VD deficiency is highly prevalent and can reach as high as $60 \%$ in postmenopausal women[6, 7]. VD deficiency is further accentuated in southern regions where there is less annual SR exposure, with up to $100 \%$ of postmenopausal women and $96 \%$ of school-aged children having VD deficiency in the city of Punta Arenas (extreme south; latitude $53^{\circ} \mathrm{S}$ ), and most of the population having 25OHD in range of severe VD deficiency $(<30 \mathrm{nmol} / \mathrm{l})[8,9]$.

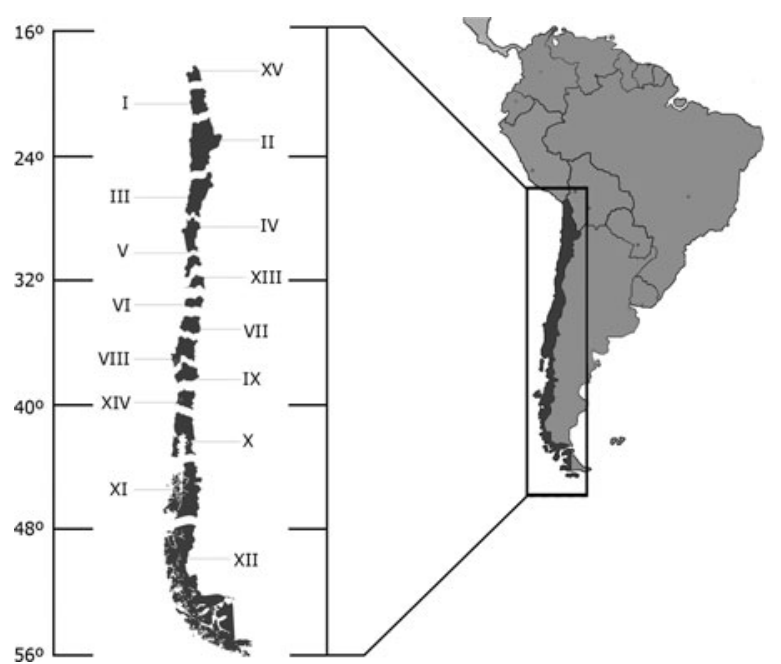

Fig. 1. Geographical distribution of regions in Chile.

Despite the large latitude range of Chile, the country has a relatively homogenous ethnic background composed of a mixture of European, mainly Spanish, and indigenous ethnicities. In addition, Chile has a highquality National TB Program since 1973 that provides free, guaranteed, and centralized access to TB diagnosis and treatment for the entire population. TB notifications collected in the national electronic $\mathrm{TB}$ record database are mandatory and supervised by the regional TB program centers by monthly cross-checking of the daily compulsory TB cases notifications by health professionals, compulsory laboratory notifications for positive Mycobacterium tuberculosis (MTB) cultures, and monthly report of $\mathrm{TB}$ cases under treatment at any local health clinic[10]. This setting provides the unique opportunity to study the relations of latitude and SR on TB in one country. The objective of this study was to evaluate the association of regional SR (a proxy of VD status) with TB incidence, admission, and mortality rates in Chile. We hypothesized that regional SR has inverse correlations with TB incidence, admission, and mortality rates.

\section{METHODS}

We retrospectively reviewed the mandatory disease notifications, hospital admissions, and population mortality databases from the Department of Health Statistics and Information of the Chilean Ministry of Health between January 2001 and December 2011. All three databases are prospectively collected by the Chilean Ministry of Health on a daily basis throughout the entire country and are publicly available for research 
purposes[11]. In these three databases, the International Classification of Diseases, 10th Revision (ICD-10) is used for coding of diagnosis. No data linkage is available across databases and patient information is de-identified. TB was identified by the following ICD-10 codes: A15 (respiratory TB, bacteriologically and histologically confirmed), A16 (respiratory TB, not confirmed bacteriologically or histologically), A17 (TB of nervous system), A18 (TB of other organs), and A19 (miliary TB). The authors of this study had full access to the information in all three databases for the period of study.

Mandatory disease notifications are prospectively collected in Chile on a daily basis with high coverage throughout the country. Notifications of TB cases are a valid proxy of TB incidence in Chile and other countries with a high performance surveillance system and good access to healthcare[1]. In our study, TB incidence was defined as notifications of new cases of TB per 100000 population per year. Notifications of TB relapses or recurrences were excluded from our analysis. TB admission rates were calculated as hospitalizations with a discharge diagnosis of TB per 100000 population per year. Mortality rates were calculated as reported TB deaths per 100000 population per year.

Chile is divided in 15 administrative regions distributed serially from north to south (Fig. 1). The country's population is unevenly distributed, with $40 \%$ inhabiting the capital city of Santiago, located in central Chile. The national health care system is defined as 'mixed', combining public and private insurance. Middle-low socioeconomic level population is covered by public insurance ( $82 \%$ in 2009), while high socioeconomic level population is covered by private insurance $(13 \%$ in 2009). A minority of the population is either covered by the armed forces insurance or lacks insurance. The National TB program is the exclusive provider of antituberculous drugs and therapy supervisor in the country, giving free coverage to all inhabitants, regardless of health insurance status.

For each region, mean annual SR intensity data, expressed as $\mathrm{MJ} / \mathrm{m}^{2} /$ day, was obtained from the Chilean Solarimetric Registry[5]. Regional immigrant population proportions and poverty rates were extracted from the 2009 National Socioeconomic Characterization Survey from the Chilean Ministry of Social Development[12]. HIV notification rates were obtained from the Chilean Ministry of Health [13]. Prison population rates were obtained from the Chilean Ministry of Justice[14].
Trends of incidence, admission, and mortality rates across different regional SR levels were analyzed by linear regression modeling, both unadjusted and with adjustment by confounders (migration rate, HIV rate and imprisonment rate). Comparisons between two rates were analyzed by calculating Poisson rate ratio. The $95 \%$ confidence intervals $(95 \% \mathrm{CI})$ were calculated, and a two-sided $P<$ 0.05 was considered statistically significant. Statistical analyses were performed using IBM SPSS Statistics for Windows Version 22 (IBM Corporation, Armonk, NY) and R Version 3.1.2 (The R Foundation for Statistical Computing, Vienna, Austria). The REporting of studies Conducted using Observational Routinely-collected health Data (RECORD) guidelines were followed in the conduct and reporting of this study.

The Scientific Ethics Committee of the Faculty of Medicine at Pontificia Universidad Católica de Chile approved this study.

\section{RESULTS}

Over the study period (2001-2011), a total of 26691 notifications of new TB cases were registered in Chile, with an estimated incidence rate was 14.77 per 100000 population per year $(95 \%$ CI $14 \cdot 60$ 14.95). Over the 11-year study period, 21901 hospital discharges and 2908 deaths from TB diagnosis were registered. The demographic and main clinical characteristics of subjects in the three databases are shown in Table 1. The hospital admission rate for TB during the period was 12.12 per 100000 population per year (95\% CI 11.96-12.28) and the TB mortality rate was 1.61 per 100000 population per year $(95 \%$ CI 1.55-1.67). TB incidence, admissions, and mortality rates decreased steadily over the study period (Fig. 2). Geographically, TB outcomes had a bimodal distribution, with peaks in extreme northern regions at the frontier of Peru and Bolivia (Region XV and Region I, latitude $17^{\circ} 29^{\prime}-21^{\circ} 37^{\prime} \mathrm{S}$ ) and in the southernmost region with lowest SR (Region XII, latitude $48^{\circ} 39^{\prime}-56^{\circ} 32^{\prime} \mathrm{S}$ ) (Table 2). To evaluate the effect of SR on TB outcomes at a national level, we performed unadjusted linear regressions that did not show a significant association of regional SR with TB incidence ( $\beta 0.44$ (95\% CI -0.87 to 1.76$), P=0.48)$, admissions $(\beta-0.54(95 \% \mathrm{CI}-1.44$ to 0.37$), P=0.22)$, or mortality $(\beta-0.03(95 \% \mathrm{CI}-0.16$ to 0.09$), P=0.59)$.

Given the clear bimodal distribution of TB in Chile, we next explored the ecological association between known demographic TB risk factors - migration from countries with high TB rates, HIV, imprisonment, 
Table 1. Demographic and clinical characteristics of subjects included in the TB disease notifications, admissions, and mortality databases (Chile, 2001-2011)

\begin{tabular}{llll}
\hline \hline & $\begin{array}{l}\text { TB incident } \\
\text { cases }(n=26691)\end{array}$ & $\begin{array}{l}\text { TB admissions } \\
(n=21901)\end{array}$ & $\begin{array}{l}\text { TB deaths } \\
(n=2908)\end{array}$ \\
\hline Age, years (mean \pm s.D.) & $46 \cdot 6 \pm 19$ & $48 \cdot 4 \pm 18$ & $58 \cdot 4 \pm 22 \cdot 3$ \\
Gender, male (\%) & $63 \cdot 3 \%$ & $70 \cdot 6 \%$ & $72 \cdot 5 \%$ \\
Pulmonary TB (\%) & $76 \cdot 2 \%$ & $85 \cdot 6 \%$ & $86 \cdot 9 \%$ \\
Extrapulmonary TB (\%) & $23 \cdot 8 \%$ & $14 \cdot 4 \%$ & $13 \cdot 1 \%$ \\
\hline \hline
\end{tabular}

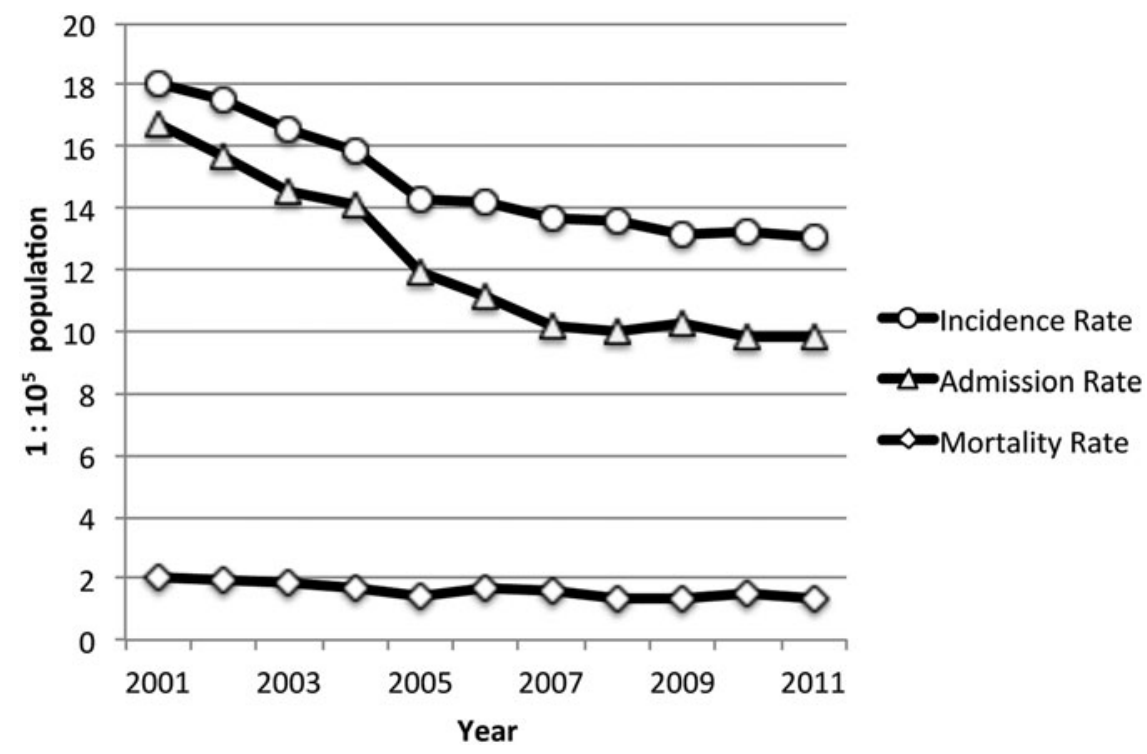

Fig. 2. Annual TB incidence rate, admission rate, and mortality rate (Chile, 2001-2011).

and poverty rates and regional $\mathrm{TB}$ incidence rates. Regional rates of these risk factors are shown in Table 3. Unadjusted linear regressions showed TB incidence and mortality in Chile were significantly associated with migration from neighboring TB-endemic countries, HIV, and imprisonment rates, and not with regional poverty (Table 4). Examining the geographical distribution of the three significant TB risk factors, these were strongly concentrated in the two northernmost regions of Chile (Region XV and Region I) that had maximal national rates of these three factors. These regions represent $2 \cdot 9 \%$ of the overall country population, but receive a large mass of migration from north-border neighboring countries Peru and Bolivia that had TB incidence rates of 106 and 135 per 100000 in year 2010, respectively, about 10-times higher than Chile[15]. In effect, the migration rate from Peru and Bolivia for year 2002 for each of these two regions (XV and I) were $8 \cdot 6$-fold $(95 \%$ CI 8.4 $8 \cdot 9)$ and $5 \cdot 7$-fold $(95 \%$ CI 5.5-5.9) respectively, the rate of the rest of the country; HIV notification rates for the period $2008-2012$ were $2 \cdot 7$-fold $(95 \%$ CI $2 \cdot 3-$ $3 \cdot 1)$ and $1 \cdot 4$-fold (95\% CI $1 \cdot 2-1 \cdot 6)$ the rate of the rest of the country; and finally, imprisonment rates during the period 2008-2012 of Region XV and Region I were $3 \cdot 6$-fold $(95 \%$ CI $3 \cdot 6-3 \cdot 7)$ and $3 \cdot 0$-fold $(95 \%$ CI $2 \cdot 95-3 \cdot 1)$ the rate of the rest of the country.

Considering the significant demographic risk factors as potential confounders of the association between SR and TB incidence, admissions, and mortality, we performed multivariable linear regressions with adjustment for migration from neighboring TB-endemic countries, HIV, and imprisonment rates. The principal assumptions of a multivariable linear regression were tested and were satisfied for all three regressions. These analyses showed an independent significant inverse linear association between SR and TB incidence rate $\left(\beta-1.05(95 \%\right.$ CI -1.73 to -0.36$), R^{2}=0.88, P=$ $0 \cdot 007)$, TB admission rate $(\beta-1.58(95 \% \mathrm{CI}-2.23$ to $\left.-0 \cdot 93), R^{2}=0 \cdot 80, P<0 \cdot 001\right)$, and TB mortality rate 
Table 2. Daily mean SR, TB incidence rate, TB admission rate and TB mortality rate, by region (Chile, 2001-2011)

\begin{tabular}{lllll}
\hline \hline Region* & $\begin{array}{l}\text { Mean SR } \\
\left(\mathrm{MJ} / \mathrm{m}^{2} / \text { day }\right)\end{array}$ & $\begin{array}{l}\text { TB incidence } \\
\text { rate }\left(1: 10^{5} \text { pop./year }\right)\end{array}$ & $\begin{array}{l}\text { TB admission } \\
\text { rate }\left(1: 10^{5} \text { pop./year }\right)\end{array}$ & $\begin{array}{l}\text { TB mortality } \\
\text { rate }\left(1: 10^{5} \text { pop./year }\right)\end{array}$ \\
\hline XV & $19 \cdot 00$ & $40 \cdot 30$ & $21 \cdot 83$ & $4 \cdot 14$ \\
I & $19 \cdot 13$ & $28 \cdot 89$ & $23 \cdot 40$ & $1 \cdot 97$ \\
II & $20 \cdot 23$ & $12 \cdot 20$ & $8 \cdot 61$ & $1 \cdot 48$ \\
III & $18 \cdot 17$ & $18 \cdot 12$ & $10 \cdot 81$ & $1 \cdot 90$ \\
IV & $17 \cdot 85$ & $11 \cdot 49$ & $8 \cdot 56$ & $1 \cdot 25$ \\
V & $14 \cdot 71$ & $12 \cdot 59$ & $12 \cdot 28$ & $1 \cdot 50$ \\
XIII & $14 \cdot 92$ & $13 \cdot 93$ & $9 \cdot 19$ & $1 \cdot 28$ \\
VI & $15 \cdot 21$ & $10 \cdot 84$ & $10 \cdot 22$ & $1 \cdot 44$ \\
VII & $15 \cdot 34$ & $12 \cdot 08$ & $9 \cdot 33$ & $1 \cdot 36$ \\
VIII & $14 \cdot 51$ & $17 \cdot 53$ & $16 \cdot 44$ & $2 \cdot 25$ \\
IX & $12 \cdot 85$ & $14 \cdot 08$ & $16 \cdot 63$ & $1 \cdot 72$ \\
XIV & $11 \cdot 50$ & $15 \cdot 47$ & $19 \cdot 58$ & $2 \cdot 00$ \\
X & $10 \cdot 60$ & $16 \cdot 98$ & $15 \cdot 17$ & $2 \cdot 39$ \\
XI & $10 \cdot 89$ & $14 \cdot 49$ & $13 \cdot 76$ & $2 \cdot 54$ \\
XII & $8 \cdot 16$ & $23 \cdot 87$ & $25 \cdot 91$ & 29 \\
\hline \hline
\end{tabular}

* Listed in geographical order (from north to south).

Table 3. Migration rate from TB-endemic countries, HIV rate, and imprisonment rate, by region in Chile

\begin{tabular}{lllll}
\hline \hline & $\begin{array}{l}\text { Migration rate from } \\
\text { Peru and Bolivia } \\
\text { (\% pop./year) 2002 }\end{array}$ & $\begin{array}{l}\text { HIV rate } \\
\left(1: 10^{5} \text { pop./5-year }\right. \\
\text { period) } 2008-2012\end{array}$ & $\begin{array}{l}\text { Prison rate } \\
\left(1: 10^{3} \text { pop./year) }\right. \\
2008-2012\end{array}$ & $\begin{array}{l}\text { Poverty rate } \\
\text { \% pop./year) } \\
2011\end{array}$ \\
\hline XV & $2 \cdot 72$ & $96 \cdot 8$ & $10 \cdot 4$ & $15 \cdot 7$ \\
I & $1 \cdot 70$ & $49 \cdot 3$ & $8 \cdot 6$ & $13 \cdot 1$ \\
II & $0 \cdot 62$ & $44 \cdot 2$ & $4 \cdot 1$ & $7 \cdot 5$ \\
III & $0 \cdot 10$ & $31 \cdot 4$ & $3 \cdot 9$ & $13 \cdot 3$ \\
IV & $0 \cdot 07$ & $29 \cdot 6$ & $3 \cdot 1$ & $15 \cdot 3$ \\
V & $0 \cdot 09$ & $30 \cdot 7$ & $3 \cdot 3$ & $16 \cdot 9$ \\
XIII & $0 \cdot 51$ & $49 \cdot 2$ & $2 \cdot 9$ & $11 \cdot 5$ \\
VI & $0 \cdot 04$ & $15 \cdot 8$ & $3 \cdot 1$ & $10 \cdot 1$ \\
VII & $0 \cdot 03$ & $16 \cdot 0$ & $2 \cdot 5$ & $21 \cdot 5$ \\
VIII & $0 \cdot 03$ & $24 \cdot 1$ & $2 \cdot 2$ & $22 \cdot 9$ \\
IX & $0 \cdot 02$ & $17 \cdot 0$ & $2 \cdot 7$ & $17 \cdot 5$ \\
XIV & $0 \cdot 03$ & $29 \cdot 2$ & $3 \cdot 2$ & 15 \\
X & $0 \cdot 02$ & $39 \cdot 6$ & $2 \cdot 4$ & $9 \cdot 8$ \\
XI & $0 \cdot 03$ & $28 \cdot 6$ & $2 \cdot 4$ & $5 \cdot 8$ \\
XII & $0 \cdot 02$ & $28 \cdot 4$ & $2 \cdot 4$ & \\
\hline
\end{tabular}

* Listed in geographical order (from north to south).

$\left(\beta-0.15(95 \% \mathrm{CI}-0 \cdot 23\right.$ to $-0 \cdot 07), R^{2}=0 \cdot 82, P=$ $0 \cdot 002)$.

Provided that potential limitations of linear regression models applied on ecological data may be a source of bias[16], we decided to confirm the association of SR and TB outcomes by assessing these relations excluding the two northernmost regions with highest rates of confounders from latitudinal analyses. Thus, we analyzed whether regional SR levels correlated with TB incidence, admission, and mortality rates between regions II and XII (latitude $21^{\circ} 38^{\prime} \mathrm{S}$ to $\left.56^{\circ} 32^{\prime} \mathrm{S}\right)$. This area covers over $3800 \mathrm{~km}$ in length and includes $97 \cdot 1 \%$ of the country population. SR between these regions linearly decreases from a mean of $20 \cdot 2 \mathrm{MJ} / \mathrm{m} 2 /$ day at region II in the north, the highest in the country, to a minimum of $8.2 \mathrm{MJ} /$ $\mathrm{m} 2 /$ day in the extreme southern region XII. Unadjusted linear regressions of SR and TB outcomes 
Table 4. Unadjusted linear regressions between migration rate from TB-endemic countries, HIV rate, imprisonment rate, and regional poverty with $T B$ incidence in Chile

\begin{tabular}{|c|c|c|c|c|c|c|c|c|c|}
\hline & \multicolumn{3}{|c|}{$\mathrm{TB}$ incidence } & \multicolumn{3}{|c|}{ TB admissions } & \multicolumn{3}{|c|}{ TB mortality } \\
\hline & $\beta$ & $95 \% \mathrm{CI}$ & $P$ & $\beta$ & $95 \% \mathrm{CI}$ & $P$ & $\beta$ & $95 \% \mathrm{CI}$ & $P$ \\
\hline Migration, $\beta(95 \% \mathrm{CI})$ & $8 \cdot 75$ & $5 \cdot 6-11 \cdot 9$ & $<0 \cdot 001$ & $3 \cdot 06$ & $-0,93$ to $7 \cdot 05$ & $0 \cdot 12$ & $0 \cdot 58$ & $0 \cdot 11-1 \cdot 05$ & $0 \cdot 019$ \\
\hline HIV rate, $\beta(95 \% \mathrm{CI})$ & $0 \cdot 32$ & $0 \cdot 18-0 \cdot 46$ & $<0.001$ & 0.09 & -0.07 to 0.25 & $0 \cdot 23$ & 0.025 & $0 \cdot 008-0 \cdot 042$ & 0.007 \\
\hline Prison rate, $\beta(95 \% \mathrm{CI})$ & $2 \cdot 80$ & $1 \cdot 7-3 \cdot 9$ & $<0 \cdot 001$ & $1 \cdot 04$ & $-0 \cdot 24$ to $2 \cdot 3$ & $0 \cdot 10$ & $0 \cdot 17$ & $0 \cdot 01-0 \cdot 33$ & $0 \cdot 035$ \\
\hline Poverty, $\beta(95 \% \mathrm{CI})$ & $-0 \cdot 05$ & -1.05 to 0.96 & $0 \cdot 93$ & 0.03 & -0.69 to 0.76 & 0.92 & $-0 \cdot 01$ & $-0 \cdot 10$ to 0.09 & $0 \cdot 91$ \\
\hline
\end{tabular}

between latitudes $21^{\circ} 38^{\prime} \mathrm{S}$ and $56^{\circ} 32^{\prime} \mathrm{S}$ showed a strong inverse association between $\mathrm{SR}$ and regional TB incidence rate $(\beta-0.62 \quad(95 \%$ CI -0.12 to $\left.-0 \cdot 05), R^{2}=0 \cdot 34, P=0 \cdot 036\right)$, regional TB admission rate $\left(\beta-1.24(95 \% \mathrm{CI}-1 \cdot 81\right.$ to $-0 \cdot 67), R^{2}=0 \cdot 68$, $P=0.001)$, and regional TB mortality rate $(\beta-0.11$ $(95 \%$ CI -0.18 to -0.05$\left.), \quad R^{2}=0.56, \quad P=0.003\right)$ (Fig. 3).

\section{DISCUSSION}

In analysis of 11 years of national data from Chile, we found that reduced regional SR - a proxy of VD deficiency - is associated with a higher TB incidence and also with epidemiological markers of TB severity (hospitalizations and mortality). Together, the data support a potential pathogenic role of VD deficiency on the incidence and severity of TB. This ecological association is strengthened by the large sample size, the long study period, and the historically very homogenous diagnostic and treatment directions of the National TB Program in Chile[10].

Previous epidemiological studies on the association of SR and TB have focused on the seasonality of TB incidence in different geographical locations, but have provided little information on latitudinal variations of $\mathrm{TB}[17-22]$. In this regard, a single study by Thorpe and co-workers showed that districts in southern regions of India have lower TB incidence rates than districts in northern regions, results that are consistent with our findings[22]. Our study is unique in that it provides large exposure heterogeneity (i.e., from tropical to circumpolar SR levels) within a relatively homogenous population in one entire country with a single high coverage national TB program. Another strength of this study is that the outcomes that were assessed (incidence, admissions, deaths) may represent different moments of the natural history of TB, showing high consistency of the association between SR and these different outcomes, which adds biological plausibility to the hypothesis that SR may be associated not only to the incidence of TB disease but also to the clinical course of TB.

Growing evidence from epidemiological and clinical studies have shown there may be an association between VD deficiency and active TB, as well as in more recent literature - an association between VD deficiency and latent TB infection, within diverse geographical locations and ethnic backgrounds[17, 23-25]. A recent meta-analysis involving 1440 cases and 2558 controls found that serum 25OHD $\leqslant 25$ nmol/1 was significantly associated with clinical TB [26]. More recently, a prospective cohort study demonstrated a significant inverse association between VD status and TB incidence at follow up in contacts (HR 0.88, 95\% CI 0.80-0.97)[27]. Thus, consistent with the association of SR with different TB outcomes found in our study, VD appears to play a prominent role at different stages of the natural history of this infection. Although profound VD deficiency has been associated with delayed sputum smear conversion in observational studies, the benefit of VD supplementation in patients with active TB is not clear, and even if some studies have shown a reduction of inflammatory markers and accelerated sputum smear conversion, others have not[28-30].

Strong risk factors for TB in Chile include high rates of migration from endemic countries, HIV co-infection, and imprisonment. At country level, in year 2012, $5.7 \%$ of all TB cases occurred in HIV-infected subjects, $7 \cdot 1 \%$ in migrants, and $3 \cdot 9 \%$ in prisoners[31]. Prisons are particularly considered a high-risk setting for TB in Chile: TB incidence was estimated at 332 per 100000 inmates between year 2002 and 2004 in Santiago[32]. In the present study we found that SR was independently associated with TB outcomes when adjusting by these confounding risk factors. Furthermore, when we excluded the extreme northern - sparsely populated - regions of the country from subsequent spatial analyses because 

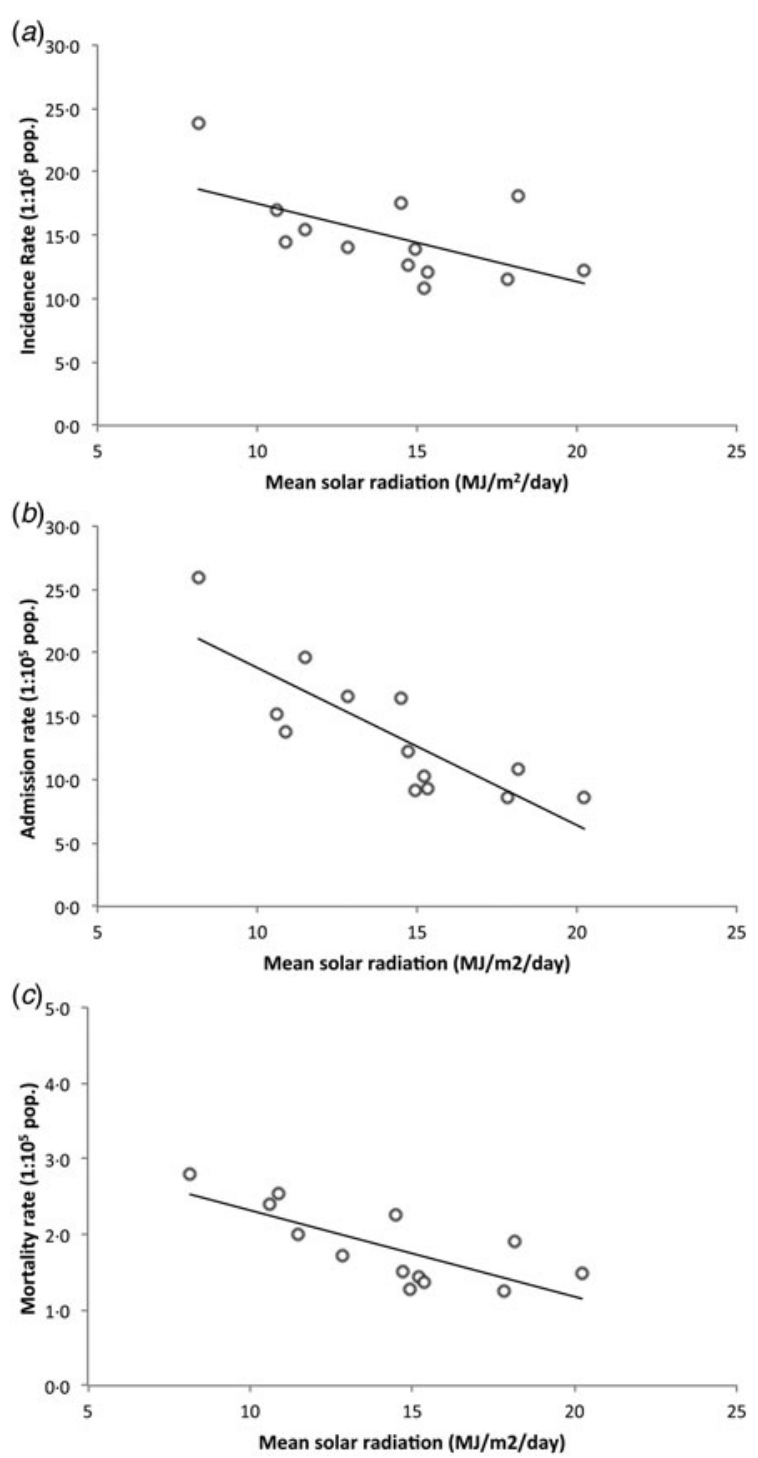

Fig. 3. Daily mean SR $v s$. TB incidence rate (a), admission rate (b), and mortality rate (c) by region (Chile, 2001-2011). Dots represent regions, black line shows linear trend. Regions XV and I were excluded. Between latitudes $21^{\circ} 38^{\prime} \mathrm{S}$ and $56^{\circ} 32^{\prime} \mathrm{S}$ there is an inverse correlation between daily mean SR and TB incidence rate, $\mathrm{TB}$ admission rate, and TB mortality rate.

they concentrated all three of these risk factors, which would have potentially acted as major confounders, the association between SR and TB outcomes was even stronger. SR in the excluded regions $(19 \cdot 1 \mathrm{MJ} /$ $\mathrm{m}^{2}$ /day) was not higher than the next consecutive region $\left(20 \cdot 2 \mathrm{MJ} / \mathrm{m}^{2} /\right.$ day $)$ that had relatively low TB rates, supporting the pathogenic role of the aforementioned risk factors in the northernmost regions and arguing against a potential effect of excess SR on higher TB incidence and severity.
Poverty is a relevant risk factor for TB even in developed countries [33, 34]. Interestingly, in the present study we did not find an association between regional poverty and TB incidence. This is possibly explained by the fact that there are wide variations in socioeconomic status within different regions in Chile, which are not necessarily reflected by aggregate statistics for each region. Thus a lack of resolution may have prevented us from identifying this as a risk factor in our analysis.

Although an association between VD deficiency and active TB has been suggested by epidemiological and clinical data, the exact mechanisms by which VD acts as an immune modulator and booster of natural immune response to MTB has only recently been explored. In human macrophages, $1 \alpha, 25[\mathrm{OH}] 2 \mathrm{D}$ and ligation of toll-like receptors causes upregulation of the intracellular VD receptor and VD 1-hydroxylase genes, resulting in induction of antimicrobial peptides such as cathelicidin and $\beta$ defensin. Cathelicidin induces fusion of the phagolysosome, which is essential for the containment, degradation, and subsequent killing of MTB[35]. Other experimental studies show that $1 \alpha, 25[\mathrm{OH}]_{2} \mathrm{D}$ also exerts its effects on innate immunity by the promotion of autophagy and the suppression of tissue remodeling and lung matrix breakdown[36, 37]. Besides its actions on innate immunity, VD exerts important effects on adaptive immunity directed against MTB. In vitro studies have shown that the antimicrobial effects of IFN- $\gamma$ are VD-dependent. Thus, VD appears to be required for cellular immunity to activate macrophagemediated antimicrobial responses to eliminate intracellular pathogens such as MTB[38].

We recognize that a limitation of current study design is the so-called ecological fallacy (i.e., the hazard of drawing inferences about the nature of individuals based on inferences about the group to which those individuals belong). The existence of inter and intra-regional variations of sun exposure among individuals is possible, as well as different dietary and vitamin supplementation habits. Nevertheless, considering previous studies on VD status in Chile[6-9], the homogeneity of the Chilean diet (generally low on VD-rich foods)[39], and lack of VD supplementation policies throughout the country, we believe it is reasonable to consider regional SR as a valid proxy of VD status of each region's inhabitants. Likewise, we believe it is plausible to suggest that low VD on an individual level may confer an increased risk of TB incidence, severity, and mortality. However, it is also possible that SR may be a proxy of other 
environmental or sociodemographic factors such as low temperatures, household overcrowding, or other medical conditions such as undernutrition. We examined whether the latter could influence the association of TB with SR. A significant association was found between SR and underweight $(\rho=0.61, P<0.05)$, and an inverse association between SR and obesity $(\rho=-0.63, P<0.05)$ (i.e., southernmost regions with lower SR have less undernutrition and higher obesity rates). Given that undernutrition is a well-known TB risk factor and obesity confers lower risk of TB[40], this inverse association between SR and weight in Chile only strengthen our findings regarding higher TB incidence in regions of lower SR. Only future, individual-based studies will confirm if the association between SR and TB truly exists. Other limitations of this study are inherent to the databases used, which were not created to answer the specific research question addressed in this study. Hospital admissions are de-identified, so it is not possible to distinguish readmissions of single patients, therefore, this may explain high TB admission rates. In addition, none of the three databases that were analyzed provided details of comorbid conditions that may potentially affect VD status or TB outcome (e.g. HIV, chronic renal failure, cancer, immunosuppression). However, the consistency of the association of SR with TB outcomes in three different databases and the large sample size covering an entire country reduces the likelihood that these risk factors were over-represented or unevenly distributed in different regions.

In summary, we found that regional SR in Chile is inversely and independently associated with incidence and severity of clinical TB, and thereby supports a potential pathogenic role of VD deficiency in TB pathogenesis. The unique conditions that exist in Chile - a country with a large latitudinal span, homogenous population and high coverage TB program provide a natural experiment as background to explore these ecological associations. We encourage further research to explore the associations of SR and VD status with TB incidence and outcomes, as well as VD supplementation trials to prevent or treat TB in VD-deficient populations.

\section{ACKNOWLEDGMENTS}

The authors would like to thank Dr Tania Herrera, Director of National TB Programme that provided data for this study. This work was partially supported by Fondo Nacional de Desarrollo Científico y
Tecnológico (M.E.B., grant number 1130600 and A. B., grant number 1130615), and Iniciativa Científica Milenio (A.B., grant P09/016-F).

\section{DECLARATION OF INTERESTS}

None.

\section{REFERENCES}

1. WHO. Global Tuberculosis Report 2015. World Health Organization, Geneva 2015 (http://www.who.int/tb/ publications/global_report/en/). Accessed February 2016.

2. Dheda K, Barry CE III, Maartens G. Tuberculosis. Lancet 2016; 387: 1211-1226.

3. Martineau AR. Old wine in new bottles: vitamin D in the treatment and prevention of tuberculosis. Proceedings of the Nutrition Society 2012; 71: 84-89.

4. Holick MF, Chen TC. Vitamin D deficiency: a worldwide problem with health consequences. The American Journal of Clinical Nutrition 2008; 87: 1080S-1086S.

5. Comisión Nacional de Energía. Irradiancia solar en territorios de la República de Chile - Registro solarimétrico 2008; 249 (http://www.termic.cl/descargas/RegistroSolarimetrico $\% 2013 \% 20 \mathrm{MB} \% 20$ prof. $\%$ 20Sarmientos.pdf). Accessed September 2015.

6. González G, et al. High prevalence of vitamin D deficiency in Chilean healthy postmenopausal women with normal sun exposure: additional evidence for a worldwide concern. Menopause 2007; 14(3 Pt1): 455-461.

7. Rodríguez PJA, Valdivia CG, Trincado MP. Fracturas vertebrales, osteoporosis y vitamina $\mathrm{D}$ en la posmenopausia. Estudio en 555 mujeres en Chile. Revista Medica de Chile 2007; 135: 31-36.

8. Brinkmann K, et al. Severe vitamin D deficiency in children from Punta Arenas, Chile: influence of nutritional status on the response to supplementation. Revista Chilena de Pediatría 2015; 86: 182-188.

9. González G, et al. [i. Existe en Chile variabilidad geográfica en la detección de hipovitaminosis D durante el invierno? Estudio multicéntrico nacional en mujeres adultas mayores sanas] [Abstract from the XV Congreso Chileno de Endocrinologia y Diabetes]. Revista Medica de Chile 2004; 132(Supl): 1290-1291, (http://dx.doi.org/ 10.4067/S0034-98872004001000017).

10. Ministerio de Salud de Chile. Programa Nacional para el Control y la Eliminación de la Tuberculosis. Normas técnicas para el control y la eliminación de la tuberculosis 2014 (http://www.sidachile.cl/guias/NormaTecnica-Tuberculosis-2014.pdf). Accessed August 2015.

11. Departamento de Estadísticas e Información de Salud (DEIS). Ministerio de Salud de Chile. [Internet] (http://deis.cl/). Accessed August 2015.

12. Encuesta de Caracterización Socioeconómica Nacional, CASEN. Inmigrantes: Síntesis de Resultados 2013 (http://observatorio.ministeriodesarrollosocial.gob.cl/ 
documentos/CASEN_2013_Inmigrantes_revisada.pdf). Accessed November 2015.

13. Departamento de Epidemiología. Ministerio de Salud de Chile. National Report: Evolution of HIV/AIDS infection in Chile, 1984-2012. Revista Chilena de Infectología 2015; 32: S17-S43.

14. Chilean Ministry of Justice. Gendarmerie of Chile-Unit of Statistics. Penitentiary Statistical Summary [Internet] (http://www.gendarmeria.gob.cl). Accessed December 2015.

15. PAHO. Tuberculosis in the Region of the Americas. Regional Report 2011. Epidemiology, Control and Financing 2012;68 (http://www.paho.org/hq/index.php? option=com_docman\&task $=$ doc_view $\&$ gid $=19510 \&$ Itemid=). Accessed December 2015.

16. Zuur A, et al. Mixed effects models and extensions in ecology with R. Series: Statistics for Biology and Health. Springer Science \& Business Media 2009; Chapt 2: 11-33.

17. Martineau AR, et al. Reciprocal seasonal variation in vitamin D status and tuberculosis notifications in Cape Town, South Africa. Proceedings of the National Academy of Sciences USA 2011; 108: 19013-19017.

18. Wingfield T, et al. The seasonality of tuberculosis, sunlight, vitamin D and household crowding. Journal of Infectious Diseases 2014; 210: 1-25.

19. Li X-X, et al. Seasonal variations in notification of active tuberculosis cases in China, 2005-2012. PLoS ONE 2013; 8(7): e68102.

20. Thorpe LE, et al. Seasonality of tuberculosis in India: is it real and what does it tell us? Lancet 2004; 364: 1613-1614.

21. Douglas AS, Strachan DP, Maxwell JD. Seasonality of tuberculosis: the reverse of other respiratory diseases in the UK. Thorax 1996; 51: 944-946.

22. Koh GCKW, et al. Tuberculosis incidence correlates with sunshine: an ecological 28-year time series study. PLoS ONE 2013; 8(3): e57752.

23. Nnoaham KE, Clarke A. Low serum vitamin D levels and tuberculosis: a systematic review and meta-analysis. International Journal of Epidemiology 2008; 37: 113-119.

24. Arnedo-Pena A, et al. Latent tuberculosis infection, tuberculin skin test and vitamin D status in contacts of tuberculosis patients: a cross-sectional and casecontrol study. BMC Infectious Diseases 2011; 11: 349.

25. Gibney KB, et al. Vitamin D deficiency is associated with tuberculosis and latent tuberculosis infection in immigrants from sub-Saharan Africa. Clinical Infectious Diseases 2008; 46: 443-446.

26. Zeng J, et al. A serum vitamin D level $<25 \mathrm{nmol} / 1$ pose high tuberculosis risk: a meta-analysis. PLoS ONE 2015; 10(5): e0126014.
27. Arnedo-Pena A, et al. Vitamin D status and incidence of tuberculosis among contacts of pulmonary tuberculosis patients. International Journal of Tuberculosis and Lung Diseases 2015; 19: 65-69.

28. Daley P, et al. Adjunctive vitamin D for treatment of active tuberculosis in India: a randomised, double-blind, placebo-controlled trial. Lancet Infectious Diseases 2015; 15: 528-534.

29. Coussens AK, et al. Vitamin D accelerates resolution of inflammatory responses during tuberculosis treatment. Proceedings of the National Academy of Sciences USA 2012; 109: 15449-15454.

30. Junaid K, et al. Genotype-independent association between profound vitamin D deficiency and delayed sputum smear conversion in pulmonary tuberculosis. BMC Infectious Diseases 2015; 15: 275.

31. Tuberculosis Informe de Situación Chile 2012. Ministerio de Salud de Chile (http://web.minsal.cl/sites/default/files/ files/tuberculosisInforme2012.pdf) Accessed December 2016.

32. García C. Tuberculosis en grupos de riesgo en la Región Metropolitana 2008. Revista Chilena de Enfermedades Respiratorias 2010; 26: 105-111.

33. Siroka A, Ponce NA, Lönnroth K. Association between spending on social protection and tuberculosis burden: a global analysis. Lancet Infectious Diseases 2016; 16: 473-479.

34. Ploubidis GB, et al. Social determinants of tuberculosis in Europe: a prospective ecological study. European Respiratory Journal 2012; 40: 925-930.

35. Borella E, et al. Vitamin D: a new anti-infective agent? Annals of the New York Academy of Sciences 2014; 1317: 76-83.

36. Yuk JM, et al. Vitamin D3 induces autophagy in human monocytes/macrophages via cathelicidin. Cell Host Microbe 2009; 6: 231-243.

37. Anand SP, Selvaraj P. Effect of 1, 25 dihydroxyvitamin $\mathrm{D}(3)$ on matrix metalloproteinases MMP-7, MMP-9 and the inhibitor TIMP-1 in pulmonary tuberculosis. Clinical Immunology 2009; 133: 126-131.

38. Fabri M, et al. Vitamin D is required for IFN-gammamediated antimicrobial activity of human macrophages. Science Translational Medicine 2011; 3: 104 ra102.

39. Crovetto M, Uauy R. Changes in processed food expenditure in the population of Metropolitan Santiago in the last twenty years. Revista Medica de Chile 2012; 140: 305-312.

40. Aibana O, et al. Nutritional status and tuberculosis risk in adult and pediatric household contacts. PLOS ONE 2016; 11: e0166333. 